\title{
A novel function of capsaicin-sensitive TRPV1 channels: Involvement in cell migration
}

\author{
J. Waning ${ }^{\mathrm{a}}$, J. Vriens ${ }^{\mathrm{b}}$, G. Owsianik ${ }^{\mathrm{b}}$, L. Stüwe ${ }^{\mathrm{a}}, \mathrm{S}_{\text {. Mally }}{ }^{\mathrm{a}}$,

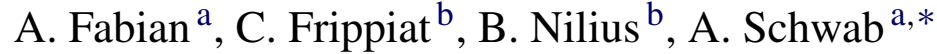 \\ a Institut für Physiologie II, Universität Münster, Robert-Koch-Str. 27b, D-48149 Münster, Germany \\ $\mathrm{b}$ Laboratorium voor Fysiologie, Katholieke Universiteit Leuven, Campus Gasthuisberg, B-3000 Leuven, Belgium
}

Received 7 November 2006; accepted 9 November 2006

Available online 20 December 2006

\begin{abstract}
Cell migration relies on a tight temporal and spatial regulation of the intracellular $\mathrm{Ca}^{2+}$ concentration $\left(\left[\mathrm{Ca}^{2+}\right]_{\mathrm{i}}\right)$. $\left[\mathrm{Ca}^{2+}\right]_{\mathrm{i}}$ in turn depends on $\mathrm{Ca}^{2+}$ influx via channels in the plasma membrane whose molecular nature is still largely unknown for migrating cells. A mechanosensitive component of the $\mathrm{Ca}^{2+}$ influx pathway was suggested. We show here that the capsaicin-sensitive transient receptor potential channel TRPV1, that plays an important role in pain transduction, is one of the $\mathrm{Ca}^{2+}$ influx channels involved in cell migration. Activating TRPV1 channels with capsaicin leads to an acceleration of human hepatoblastoma (HepG2) cells pretreated with hepatocyte growth factor (HGF). The speed rises by up to $50 \%$ and the displacement is doubled. Patch clamp experiments revealed the presence of capsaicin and resiniferatoxin (RTX)-sensitive currents. In contrast, HepG2 cells kept in the absence of HGF are not accelerated by capsaicin and express no capsaicin- or RTX-sensitive current. The TRPV1 antagonist capsazepine prevents the stimulation of migration and inhibits capsaicin-sensitive currents. Finally, we compared the contribution of capsaicin-sensitive TRPV1 channels to cell migration with that of mechanosensitive TRPV4 channels that are also expressed in HepG2 cells. A specific TRPV4 agonist, 4 $\alpha$-phorbol 12,13-didecanoate, does not increase the displacement. In summary, we assigned a novel role to capsaicin-sensitive TRPV1 channels. They are important $\mathrm{Ca}^{2+}$ influx channels required for cell migration.
\end{abstract}

(C) 2006 Elsevier Ltd. All rights reserved.

Keywords: Migration; Calcium; TRPV1; TRPV4; Capsaicin; Mechanosensitive

\section{Introduction}

Cell migration plays a pivotal role in many (patho-) physiological processes, including embryogenesis, wound healing, angiogenesis, cancer growth and inflammation [1]. It is a complex process that requires interaction between cytoskeletal reorganization [2], formation and release of cell-matrix contacts [3], exo- and endocytosis [4,5] as well as function of ion channels and transporters [6-8]. Many of the components of the cellular migration machinery are regulated by the intracellular $\mathrm{Ca}^{2+}$ concentration $\left(\left[\mathrm{Ca}^{2+}\right]_{\mathrm{i}}\right)$

\footnotetext{
Abbreviations: TRP, transient receptor potential; $\left[\mathrm{Ca}^{2+}\right]_{\mathrm{i}}$, intracellular $\mathrm{Ca}^{2+}$ concentration; HGF, hepatocyte growth factor; FCS, fetal calf serum

* Corresponding author. Tel.: +49 251 8355329; fax: +49 2518355331.

E-mail address: aschwab@uni-muenster.de (A. Schwab).
}

$[9,10]$. The important regulatory function of $\left[\mathrm{Ca}^{2+}\right]_{\mathrm{i}}$ is also reflected by the fact that $\left[\mathrm{Ca}^{2+}\right]_{i}$ is precisely controlled in a spatial and temporal manner. Many migrating cells exhibit a gradient of the intracellular $\mathrm{Ca}^{2+}$ concentration $\left(\left[\mathrm{Ca}^{2+}\right]_{\mathrm{i}}\right)$, which shows higher values in the cell body (rear) than in the lamellipodium (front) [11,12]. In addition to this spatial redistribution of $\mathrm{Ca}^{2+}$, oscillations of $\left[\mathrm{Ca}^{2+}\right]_{\mathrm{i}}$ serve as a transient component of $\mathrm{Ca}^{2+}$ signaling pathway in migrating cells [9]. In order to achieve such a complex $\left[\mathrm{Ca}^{2+}\right]_{\mathrm{i}}$ pattern, $\mathrm{Ca}^{2+}$ influx and efflux pathways must be tightly regulated. We recently showed that in migrating cells the $\mathrm{Na}^{+} / \mathrm{Ca}^{2+}$ exchanger is one of the major components of the $\mathrm{Ca}^{2+}$ efflux machinery [13]. However, despite the importance of a tightly regulated $\mathrm{Ca}^{2+}$ influx pathway there are only few studies in which $\mathrm{Ca}^{2+}$ influx channels required for cell migration were identified on a molecular level $[10,14-16]$. 
Members of the transient receptor potential (TRP) channel superfamily are good candidates for $\mathrm{Ca}^{2+}$ influx channels involved in the regulation of $\left[\mathrm{Ca}^{2+}\right]_{i}$ in migrating peripheral cells. TRP channels are expressed in almost every cell type and most of them are $\mathrm{Ca}^{2+}$ permeable $[17,18]$. Based on structural homology, TRP-related proteins are subdivided into seven subfamilies: TRPC ('Canonical'), TRPV ('Vanilloid'), TRPM ('Melastatin'), TRPP ('Polycystin'), TRPML ('Mucolipin'), TRPA ('Ankyrin') and TRPN ('NOMP') [18-20]. Interestingly, hepatocyte growth factor (HGF) modulates $\mathrm{Ca}^{2+}$ entry and mobilization [21,22]. HGF acts on cells that express the Met tyrosine kinase receptor [23]. The HGF-Met binding promotes embryological development of the central nervous system, kidney, mammary gland, and it is critical for tissue regeneration and wound healing [24]. Little is known about modulation of ion channels by HGF. We previously showed that TRPV1 and TRPV4 provide $\mathrm{Ca}^{2+}$ entry pathways in hepatoblastoma HepG2 cells, and that at least TRPV1 is modulated by HGF [25]. TRPV1, a relatively $\mathrm{Ca}^{2+}$ selective ion channel $\left(P_{\mathrm{Ca}} / P_{\mathrm{Na}} \sim 10\right)$, mediates nociception and contributes to the detection and integration of diverse chemical and thermal stimuli [26-28]. TRPV4 is a heat-activated and mechanosensitive channel [29-32] that is necessary for the maintenance of osmotic equilibrium [33]. TRPV4 that is also expressed in HepG2 cells [25], is an especially attracting candidate, as it represents a $\mathrm{Ca}^{2+}$ pathway that is activated upon changes in cell shape, e.g. during cell swelling and shear stress [34]. Moreover TRPV4 is activated by epoxyeicosatrienoic acids [31], which are important inflammatory messengers that may mediate migration of leukocytes towards sites of inflammation. Here we present the first evidence that capsaicin increases migratory activity and induces large capsaicin-sensitive currents in HGFtreated HepG2 cells. Application of capsazepine, a TRPV1 antagonist, to HGF-treated HepG2 cells strongly impairs both migration and capsaicin-sensitive currents. The TRPV4 agonist $4 \alpha$-PDD stimulates migration to a lesser extent. Thus, our data provide strong evidence that TRPV1 and TRPV4 are $\mathrm{Ca}^{2+}$ influx channels involved in the process of cell migration.

\section{Materials and methods}

\subsection{Cell culture}

HepG2 cells were obtained from the American Type Culture Collection (Manassas, VA). Cells were grown in T-flasks in Dulbecco's modified Eagle's medium (Gibco) supplemented with $2 \mathrm{mM}$ glutamine, $0.1 \mathrm{mM}$ non-essential amino acids, $1 \mathrm{mM}$ sodium pyruvate, and $10 \%$ fetal calf serum (FCS) at $37^{\circ} \mathrm{C}$ in a humidified atmosphere of $5 \% \mathrm{CO}_{2}$. Twenty-four hours before the experiments, HepG2 cells were placed in FCS-free medium ( $\mathrm{pH} 7.2$ ) supplemented or not with $20 \mathrm{ng} / \mathrm{ml}$ HGF (Research Diagnostics).

\subsection{Migration experiments}

Collagen matrices were prepared $24 \mathrm{~h}$ before migration experiments, using collagen solution (Biochrom) diluted in standard phosphate buffered saline buffer (PBS, $10 \mathrm{mM}$ phosphate buffer $\mathrm{pH} 7.4,137 \mathrm{mM} \mathrm{NaCl}, 2.7 \mathrm{mM} \mathrm{KCl}$ ) to a final concentration of $0.4 \mathrm{mg} / \mathrm{ml}$. HepG2 cells treated or not with HGF were seeded onto the collagen matrix $3 \mathrm{~h}$ before the start of the experiment. Capsaicin (Calbiochem), capsazepine (Sigma), and $4 \alpha$-PDD (Sigma) dissolved in DMSO or ethanol, were added into medium $15 \mathrm{~min}$ prior to the experiment. To discriminate effects of the solvent, appropriate amounts of DMSO or ethanol were also tested in control experiments. Alternatively, HepG2 cells were kept in a modified Ringer solution (in $\mathrm{mM}$ : $97.9 \mathrm{NaCl}, 30 \mathrm{KCl}, 1.2 \mathrm{CaCl}_{2}$, $0.8 \mathrm{MgCl}_{2}, 5$ glucose, 10 HEPES, pH 7.2 with $1 \mathrm{~N} \mathrm{NaOH}$ ) containing HGF and capsaicin throughout the entire course of the migration experiment. The culture flasks with the cells were placed into an electronically controlled heating chamber $\left(37^{\circ} \mathrm{C}\right)$ on the stage of an inverted Axiovert 25 or Axiovert 40C microscopes (Carl Zeiss) and migration was monitored by time lapse video recordings as described previously $[13,35]$. The video signal was captured in 10 min intervals for $5 \mathrm{~h}$ with HiPic software (Hamamatsu). The circumferences of cells were defined with Amira software (Mercury Computer Systems, Düsseldorf, Germany) and the displacement (given in $\mu \mathrm{m}$ ) was calculated for each cell as the distance covered by the cell center within $5 \mathrm{~h}$. The velocity ( $v$; given in $\mu \mathrm{m} / \mathrm{min}$ ) was calculated from the movement of the cell center over time, using a three-point difference $[13,35]$. The displacement is a measure of sustained directional migration while the velocity also strongly reflects lamellipodial dynamics.

\subsection{Patch clamp experiments}

The standard extracellular solution for electrophysiological measurements contained (in $\mathrm{mM}$ ) $150 \mathrm{NaCl}, 6 \mathrm{CsCl}$, $1 \mathrm{MgCl}_{2}, 1.5 \mathrm{CaCl}_{2}, 10$ glucose, 10 Hepes, pH 7.4 with $\mathrm{NaOH}$. The pipette solution was composed of (in $\mathrm{mM}$ ) 20 $\mathrm{CsCl}, 100$ cesium aspartate, $1 \mathrm{MgCl}_{2}, 4 \mathrm{Na}_{2} \mathrm{ATP}, 10$ Hepes, 10 EGTA, $5.56 \mathrm{CaCl}_{2}$. The free $\mathrm{Ca}^{2+}$ concentration in this solution reaches $\approx 200 \mathrm{nM}$.

Whole-cell membrane currents were measured with an EPC-10 (HEKA Elektronik; sampling rate, $1 \mathrm{~ms}$; 8-Pole Bessel filter $2.9 \mathrm{kHz}$ ) using ruptured patches. Patch electrodes had a dc resistance between 2 and $4 \mathrm{M} \Omega$ when filled with intracellular solution. $\mathrm{An} \mathrm{Ag}-\mathrm{AgCl}$ wire was used as a reference electrode. Capacitance and access resistance were monitored continuously. Between $50 \%$ and $70 \%$ of the series resistance was electronically compensated to minimize voltage errors. Currents were evoked using a ramp protocol, consisting of a voltage step from the holding potential of $0 \mathrm{mV}$ to $-100 \mathrm{mV}$ followed by a $400 \mathrm{~ms}$ linear ramp to $+100 \mathrm{mV}$, which was repeated every $2 \mathrm{~s}$. To calculate current densities, cell membrane capacitance values were used. 


\subsection{Protein extraction and immunodetection}

Whole cell extracts from HepG2 cells incubated or not with HGF were isolated using a protocol described previously [25]. Briefly, HepG2 cells were washed with a cold PBS. Cells were lysed in lysis buffer (PBS with $1.5 \%$ Triton X-100, $0.2 \%$ sodium dodecylsulfate (SDS), $1 \mathrm{mmol} / \mathrm{l}$ phenylmethylsulfonyl fluoride (PMSF) and protease inhibitors $(10 \mu \mathrm{g} / \mathrm{ml}$ leupeptin and antipain, $2 \mu \mathrm{g} / \mathrm{ml}$ chymostatin and pepstatin)) using a syringe with $0.6 \mathrm{~mm}$ needle. After a 30-min incubation on ice, cell lysates were clarified by centrifugation at $14,000 \times g$ for $15 \mathrm{~min}$ at $4{ }^{\circ} \mathrm{C}$. Samples $(40 \mu \mathrm{g})$ were solubilized in sample buffer $(240 \mathrm{mmol} / 1$ Tris, $\mathrm{pH} 6.8,30 \%$ glycerol, $6 \%$ sodium dodecyl sulfate (SDS), 3\% dithiothreitol, $0.015 \%$ bromophelol blue) by heating to $56^{\circ} \mathrm{C}$ for $15 \mathrm{~min}$ and then subjected to $8 \%$ SDS-polyacrylamide gel electrophoresis (SDS-PAGE), blotted onto a PVDF membrane (Bio-Rad), and probed with purified polyclonal goat anti-TRPV1 (Santa Cruz Biotechnology, Inc.) or monoclonal mouse anti- $\alpha$-tubulin (Sigma) antibodies. To control specificity of TRPV1 immunodetection, anti-TRPV1 antibodies were pre-incubated with 10-fold excess of the specific blocking peptide (Santa Cruz Biotechnology, Inc.) for $90 \mathrm{~min}$ and then used for immunodetection. Immunoreactive complexes were visualized by chemiluminescence, using anti-goat or anti-mouse IgG antibodies conjugated to horseradish peroxidase (Amersham Biosciences). Densitometric analysis was performed using TotalLab ver. 2003.03 software (Nonlinear Dynamics Ltd.). When required, the bound antibodies were removed using Re-Blot Plus mild antibodies stripping solution according to the manufacturer's instructions (Chemicon International, Inc.).

\subsection{Measurements of the intracellular $\mathrm{Ca}^{2+}$ concentration}

On the day of the experiment, HepG2 cells were seeded onto collagen-coated glass cover slips and stored for $3 \mathrm{~h}$ in HEPES-buffered culture medium ( $\mathrm{pH} 7.2)$ at $37^{\circ} \mathrm{C}$ (all subsequent solutions and steps were at $37^{\circ} \mathrm{C}$ ). After variable periods of preincubation with or without capsaicin, the cells were loaded with the $\mathrm{Ca}^{2+}$ indicator Fura-2 (3 $\mu \mathrm{M}$; Molecular Probes) for $15 \mathrm{~min}$ and immediately placed on the stage of an inverted Axiovert 200 microscope (Carl Zeiss). During experiments, the cells were continuously superfused with Ringer's solution (in mM: $\mathrm{NaCl} 122.5, \mathrm{KCl} 5.4, \mathrm{MgCl}_{2} 0.8, \mathrm{CaCl}_{2}$ 1.2, $\mathrm{NaH}_{2} \mathrm{PO}_{4}$ 1.0, D-glucose 5.5, HEPES 10.0, pH 7.2), which contained, if applied, the same amount of capsaicin

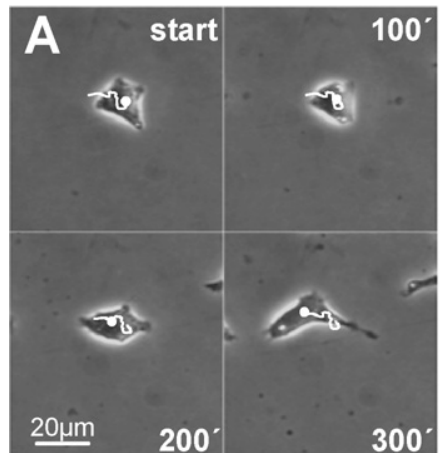

control

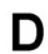

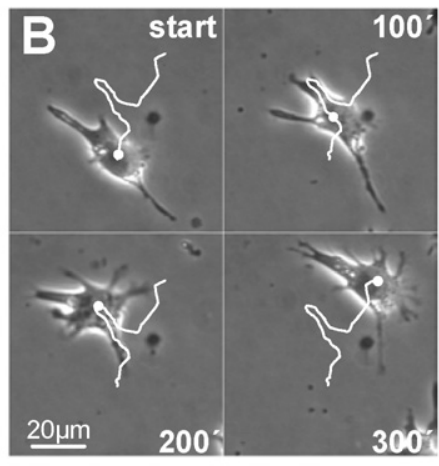

capsaicin

E

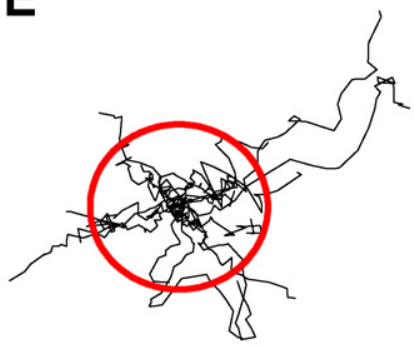

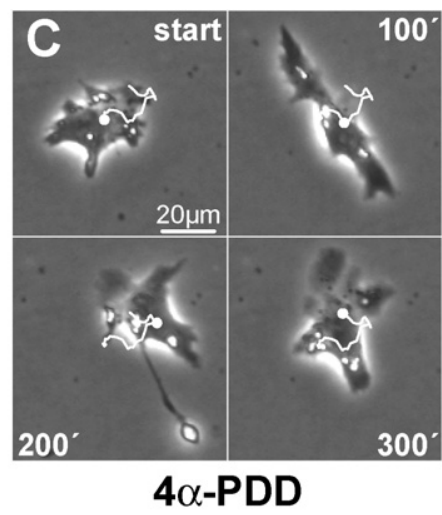

$\mathbf{F}$

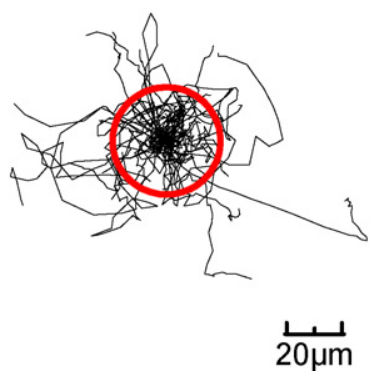

Fig. 1. Analysis of migration experiments. A, B and C show time lapse video micrographs taken in 100 min intervals. They show the paths of HepG2 cells during a $5 \mathrm{~h}$ period. The circles indicate the current position along the trajectories. Cells are pretreated with HGF $(20 \mathrm{ng} / \mathrm{ml}$ for $24 \mathrm{~h})$. The figure illustrates the stimulatory effect of TRPV1 and TRPV4 activation on HepG2 cell migration. The distance the cell moved under control conditions (A) was shorter than in the presence of $100 \mathrm{nM}$ capsaicin (B) or $1 \mu \mathrm{M} 4 \alpha$-PDD (C). D, E and F depict the trajectories of individual cells shifted to a common starting point. Cells were monitored under control conditions (D) and in the presence of $100 \mathrm{nM}$ capsaicin (E), or $1 \mu \mathrm{M} 4 \alpha-\mathrm{PDD}(\mathrm{F})$. The circles indicate the mean distances covered within $5 \mathrm{~h}$ 
as in the initial preincubation step. Excitation wavelength alternated between $334 \mathrm{~nm}$ and $380 \mathrm{~nm}$. The emitted fluorescence was monitored at $500 \mathrm{~nm}$, using the CoolSnap camera (Visitron Systems) and the monochromator and data acquisition were controlled by the Metafluor software (Visitron). Average fluorescence intensities (corrected for background fluorescence) were measured in 20-s intervals for 10-20 min in demarcated regions of interest placed over the projected cell surface. $\left[\mathrm{Ca}^{2+}\right]_{\mathrm{i}}$ was calculated as described elsewhere [36].

\subsection{Statistics}

All experiments were repeated at least three times and data are expressed as mean value \pm S.E.M. Significant difference between individual groups was tested by using Student's $t$-test $(p<0.05)$.

\section{Results}

\subsection{Capsaicin and $4 \alpha-P D D$ stimulate migration of HepG2 cells}

HepG2 cells preincubated with $\mathrm{HGF}(20 \mathrm{ng} / \mathrm{ml}, 24 \mathrm{~h}$ ) displayed weak migratory activity with rather little lamellipodial dynamics (Fig. 1A and Video 1 in supplementary data). Direct application of $100 \mathrm{nM}$ capsaicin, a specific TRPV1 activator, enhanced migration (Fig. 1B and Video 2 in supplementary data). Capsaicin-stimulated HepG2 cells covered within $5 \mathrm{~h}$ of the experiment $30.3 \pm 4.4 \mu \mathrm{m}$ with a velocity of $0.19 \pm 0.02 \mu \mathrm{m} / \mathrm{min}(n=29)$, whereas the control cells without capsaicin application within the same time of experiment covered a smaller distance of $15.7 \pm 1.7 \mu \mathrm{m}$ with a velocity of $0.13 \pm 0.01 \mu \mathrm{m} / \mathrm{min}$ ( $n=64$; Fig. $1 \mathrm{D}$ and E; Fig. $2 \mathrm{~A}$ and $\mathrm{B})$. The effect of capsaicin on migration of HGF-treated HepG2 cells was dose-dependent, displaying an increased displacement and velocity at low concentrations $(10 \mathrm{nM}$ and $100 \mathrm{nM})$, whereas higher concentrations $(1 \mu \mathrm{M}$ and $10 \mu \mathrm{M})$ did not show any effect (Supplementary Fig. 1). Furthermore, application of $20 \mu \mathrm{M}$ capsazepine, a specific TRPV1 antagonist, completely abolished the stimulatory effect of capsaicin on migration of HGF-treated HepG2 cells, leading to the displacement of $5.70 \pm 0.9 \mu \mathrm{m}$ within $5 \mathrm{~h}$ and the velocity of $0.05 \pm 0.003 \mu \mathrm{m} / \mathrm{min}(n=39$; see Fig. $2 \mathrm{~A}$ and B). The application of $1 \mu \mathrm{M} 4 \alpha-\mathrm{PDD}$, the most specific TRPV 4 agonist, led predominantly to increased lamellipodial dynamics in HGF treated HepG2 cells (Video 3). This was reflected by a rise of the velocity to $0.17 \pm 0.02 \mu \mathrm{m} / \mathrm{min}$ (see Fig. 2B and Video 3). The displacement, however, was not statistically different from control conditions $(19.4 \pm 2.1 \mu \mathrm{m}$ within $5 \mathrm{~h}$; $n=55$; see Fig. 2A). Interestingly, in HepG2 cells not treated with HGF, capsaicin and $4 \alpha$-PDD did not evoke any further increase of migration (Fig. 2A and B). Taken together, all these results indicated the involvement of TRPV1 and most likely TRPV4 in migration of HGF-treated HepG2 cells.
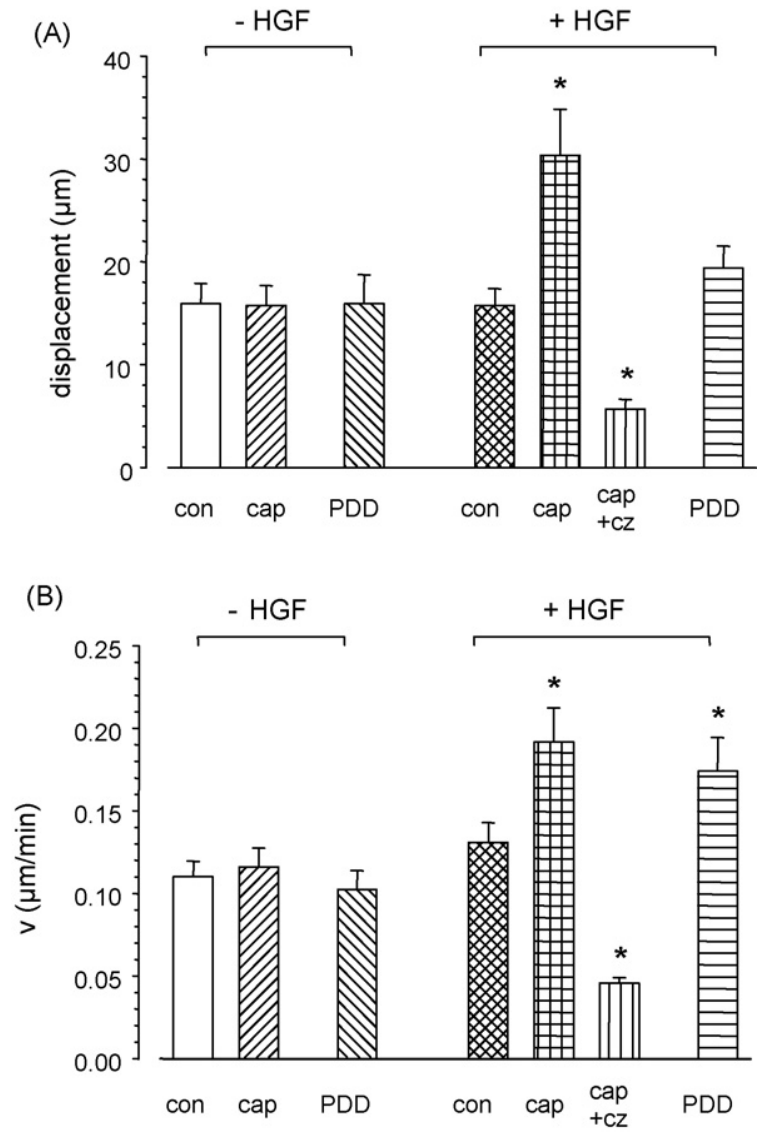

Fig. 2. Summary of migration experiments. (A) Compares the displacement and (B) the velocity of HepG2 cells under different conditions. (*) $<0.05$ with respect to control experiments with HGF only.

\subsection{HGF regulates TRPVI channel function in HepG2 cells}

Previous results obtained via calcium imaging experiments clearly demonstrate that the HGF treatment modulates the TRPV1-dependent $\mathrm{Ca}^{2+}$ entry pathway in migrating HepG2 cells [25]. In order to further investigate the role of TRPV1 channels in migration of HepG2 cells, we performed series of whole-cell patch-clamp experiments. Direct superfusion with $10 \mu \mathrm{M}$ capsaicin (Fig. 3B and D) or $5 \mu \mathrm{M}$ resiniferatoxin (RTX) (Fig. 3C) evoked large whole cell currents in HepG2 cells pretreated with HGF, while no additional current was observed in non-HGF-treated HepG2 cells (Fig. 3A and C). These capsaicin-induced currents were partially blocked by $20 \mu \mathrm{M}$ capsazepine (Fig. 3B), demonstrating that TRPV1 was a $\mathrm{Ca}^{2+}$ influx channel involved in migration of HGF-treated HepG2 cells.

In order to investigate the effect of HGF on the functional expression of TRPV1, we performed the Western blot analysis of whole-cell extracts prepared from HGF-treated and non-treated HepG2 cells. Immunodetection with specific anti-TRPV1 antibodies led to the identification of a $85-90 \mathrm{kDa}$ band that corresponds to the predicted molecular 
(A)

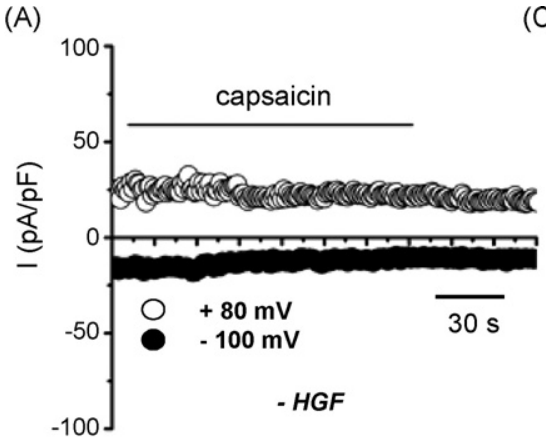

(B)

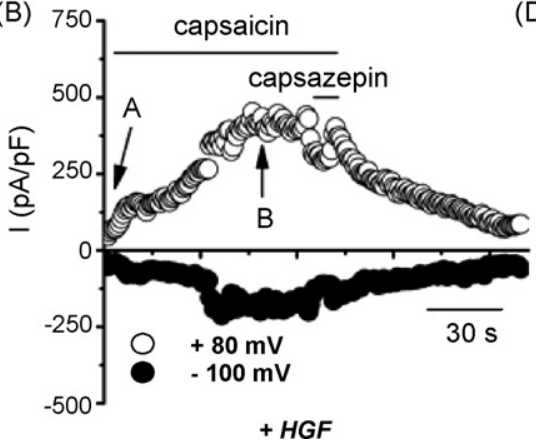

(C)

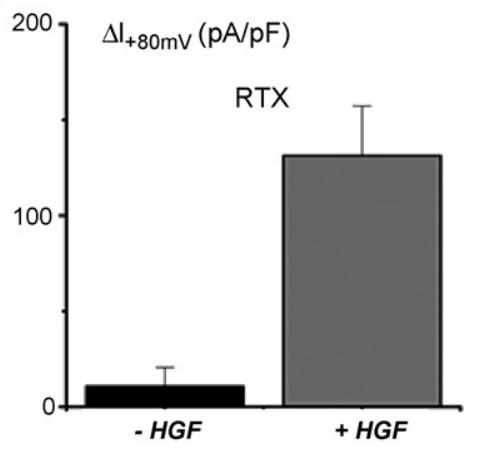

(D)

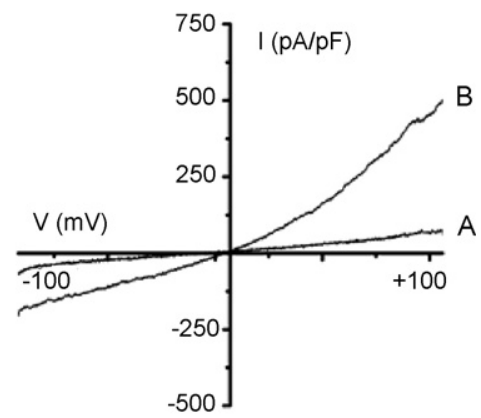

Fig. 3. Electrophysiological analysis of TRPV1 currents in HepG2 cells. A and B show the analysis of two whole-cell patch clamp experiments in HepG2 cells without (A) and with HGF pretreatment (B). Outward currents measured at $+80 \mathrm{mV}$ (open circles) and inward currents at $-100 \mathrm{mV}$ (black circles). Capsaicin-activated current could be partially blocked by capsazepine $(20 \mu \mathrm{M})$ in HGF-treated HepG2 cells (B). (C) Maximal increases in outward-current density at $+80 \mathrm{mV}$ upon stimulation with $5 \mu \mathrm{M}$ resiniferatoxin (RTX). (D) Current-voltage relation obtained at the indicated time points in HGF-treated HepG2 cells after application of capsaicin.

weight of TRPV1 (Fig. 4A). Detection of this band was completely absent when the Western blot membrane was probed with the anti-TRPV1 antibodies incubated with the specific blocking peptide, confirming immunodetection of TRPV1 channels in HepG2 cells (Fig. 4A). Densitometric analysis showed no differences in TRPV1 band intensities in either HGF-treated or non-treated HepG2 cells (Fig. 4B), suggesting that HGF could either modulate activation of TRPV1 channels already inserted in the plasma membrane or enhance recruitment of the channels to the plasma membrane.

\subsection{Hyperpolarization of cell membrane is required for TRPV1-dependent migration of HepG2 cells}

HGF increases $\mathrm{K}^{+}$channel activity and thereby hyperpolarizes the cell membrane potential [37]. Such hyperpolarization would potentially have an effect on cell migration as a result of an increased driving force for inward currents through TRPV1 channels. In order to test this hypothesis we carried out migration experiments in which we attenuated the effects of a possible membrane hyperpolarization by incubation of HepG 2 cells in a Ringer's solution that contained $30 \mathrm{mM} \mathrm{K}^{+}$. Under these conditions, $100 \mathrm{nM}$ capsaicin did not have any effect on migration of HepG2 cells, indicating that hyperpolarization of the cell membrane is essential for the TRPV1-dependent stimulation of HepG2 cell migration. The displacement was $22.7 \pm 2.9 \mu \mathrm{m}(n=36)$ and $22.9 \pm 3.9 \mu \mathrm{m}(n=36)$ in the presence and absence of capsaicin, respectively.

\subsection{Capsaicin increases $\left[\mathrm{Ca}^{2+}\right]_{i}$}

Physiologically, $\mathrm{Ca}^{2+}$ ions are the major charge carriers for TRPV1-mediated currents. Hence, TRPV1 activation in HGF-treated HepG2 cells was expected to lead to an increase of $\left[\mathrm{Ca}^{2+}\right]_{i}$. Fig. 5 summarizes the acute effects and those of 30 min preincubation of HGF-treated HepG2 cells with different capsaicin concentrations. This treatment resulted in a significant increase of $\left[\mathrm{Ca}^{2+}\right]_{i}$. In the vast majority of cells, the initial rise of $\left[\mathrm{Ca}^{2+}\right]_{i}$ was slow and steady. Only in the presence of $100 \mathrm{nmol} / \mathrm{l}$ capsaicin the rise of $\left[\mathrm{Ca}^{2+}\right]_{\mathrm{i}}$ also had a transient component as shown in Fig. 5A. The maximal long-term increase of $\left[\mathrm{Ca}^{2+}\right]_{i}$ was evoked by $1 \mu \mathrm{M}$ capsaicin application, while $10 \mu \mathrm{M}$ capsaicin elicited a much smaller $\left[\mathrm{Ca}^{2+}\right]_{i}$ increase, most likely due to desensitization of TRPV1. Importantly, the elevation of $\left[\mathrm{Ca}^{2+}\right]_{i}$ was sustained also at later time points relevant for the time course of migration experiments. $\left[\mathrm{Ca}^{2+}\right]_{\mathrm{i}}$ of HepG2 cells was still at $158 \pm 11 \mathrm{nmol} / \mathrm{l}(n=36)$ after $3 \mathrm{~h}$ in the presence of $100 \mathrm{nmol} / \mathrm{l}$ capsaicin, and it was $449 \pm 23 \mathrm{nmol} / \mathrm{l}(n=29)$ after $5 \mathrm{~h}$ of $1 \mathrm{nmol} / 1$ capsaicin. 
(A)

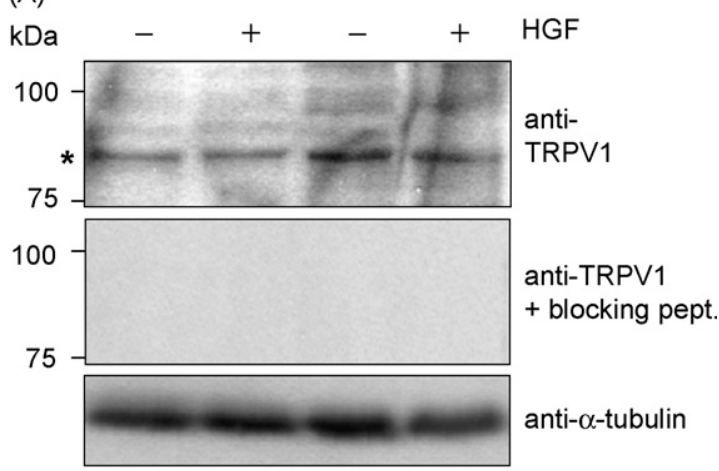

(B)

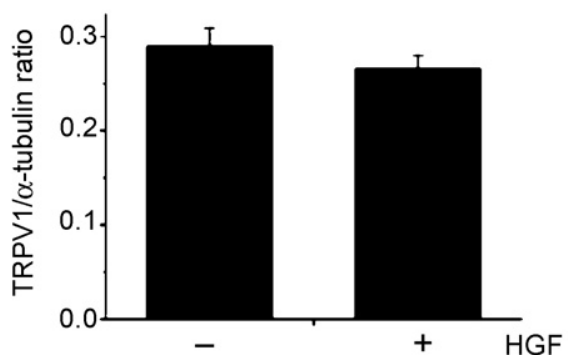

Fig. 4. Detection of TRPV1 in HepG2 cells. (A) Whole cell extracts $(40 \mu \mathrm{g})$ isolated from HepG2 cells incubated (+) or not (-) with HGF $(20 \mathrm{ng} / \mathrm{ml}$; $24 \mathrm{~h}$ ) were separated by SDS-PAGE and probed with anti-TRPV1 antibodies. As a control of TRPV1 detection, anti-TRPV1 antibodies were pre-incubated with 10 -fold excess of the blocking peptide for $90 \mathrm{~min}$ and then used for immunodetection. The equal loading of protein extracts was assessed by reblotting with anti- $\alpha$-tubulin antibodies. (B) Densitometric analysis of the TRPV1 protein level in HepG2 cells incubated (+) or not (-) with HGF. Data from three independent sets of experiments were normalized to $\alpha$-tubulin and presented as TRPV $1 / \alpha$-tubulin protein ratio.

\section{Discussion}

Function of the $\mathrm{Ca}^{2+}$ influx machinery is important for the maintenance of regulated temporal and spatial $\left[\mathrm{Ca}^{2+}\right]_{i}$ gradients that control cell migration. It has been proposed that mechanosensitive cation channels could play a crucial role in mediating $\mathrm{Ca}^{2+}$ influx needed for migration of peripheral cells $[1,38]$. Nevertheless, we show here for the first time that TRPV1 is a major physiological $\mathrm{Ca}^{2+}$ influx channel required for migration of HGF-pretreated human hepatoblastoma HepG2 cells. In contrast, stimulation of the mechanosensitive TRPV4 channel [29,39-41] has a smaller effect on migration. Our observations on $4 \alpha$-PDD-stimulated HepG 2 cells are consistent with previous findings obtained in fibroblasts that showed a similar migration rate as HepG2 cells [38]. Blocking mechanosensitive $\mathrm{Ca}^{2+}$-influx at the leading edge of the lamellipodium reduced the velocity of fibroblasts [38]. Here we show that activation of mechanosensitive TRPV4 channels led to increased lamellipodial dynamics pointing to the importance of the mechanosensitivity of the frontal region of migrating cells.

Capsaicin, a pungent substance in red chili peppers, is a specific agonist of TRPV1 [26]. It has been previously reported that intradermal application of capsaicin to wild type mice leads to maturation of dendritic cells and their
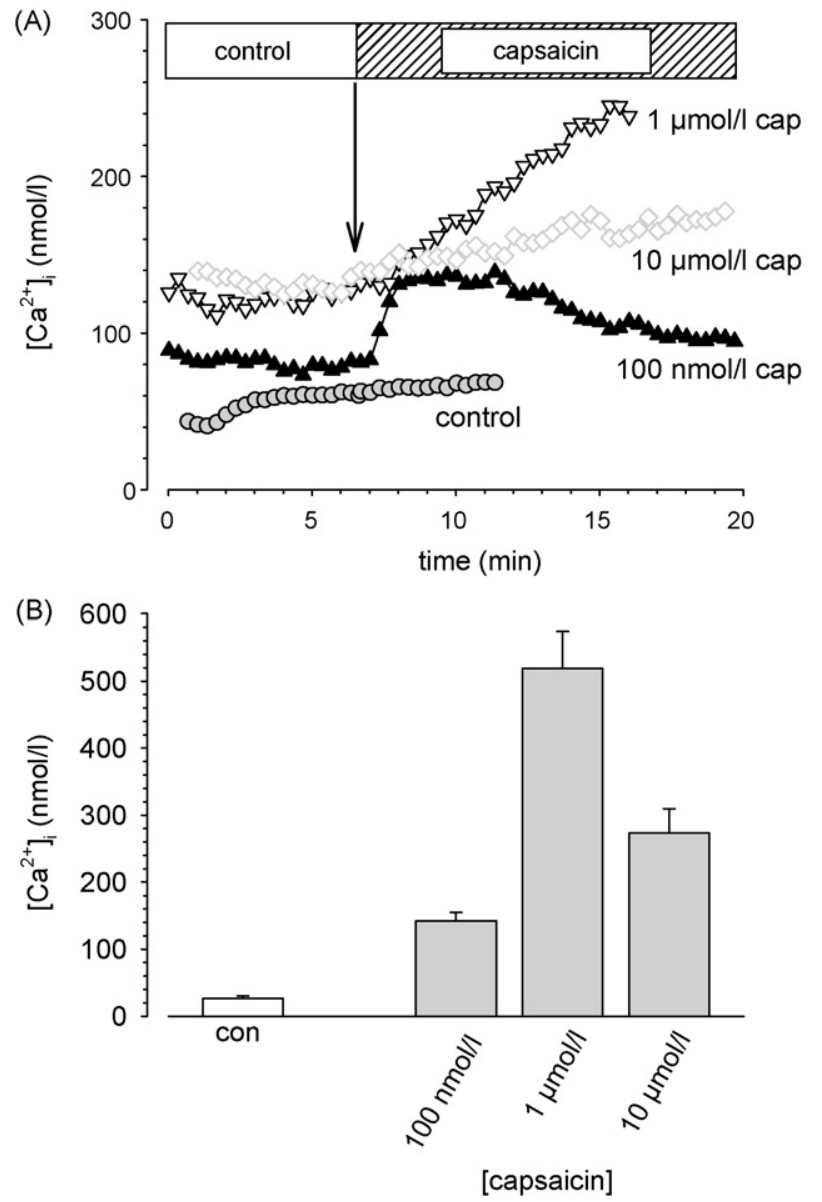

Fig. 5. Measurements of the intracellular $\mathrm{Ca}^{2+}$ concentration. (A) Shows the acute effect of the application of various concentrations of capsaicin. (B) Depicts the mean $\left[\mathrm{Ca}^{2+}\right]_{\mathrm{i}}$ reached after a $30 \mathrm{~min}$ incubation period with capsaicin. $1 \mu \mathrm{mol} / 1$ capsaicin produces the strongest increase of the intracellular $\mathrm{Ca}^{2+}$ concentration.

accumulation in the draining lymph nodes. Such stimulation has not been observed in TRPV1 knock-out mice, suggesting a link between TRPV1 and migration of dendritic cells to the draining lymph nodes [42]. However, since TRPV1 channels are not expressed in dendritic cells, the effect of capsaicin on dendritic cells was interpreted as an indirect one involving neurogenic inflammatory cascades in the skin [43]. More recently, TRPV1 seems to be involved in migration of neutrophils via leukotriene $\mathrm{B}_{4}$ receptor $\left(\mathrm{LTB}_{4}\right)$ activation. Compounds that block both $\mathrm{LTB}_{4}$ and TRPV1 activation highly attenuate neutrophil activation and migration [44]. Here, we provide a direct proof on a single cell level that stimulation of TRPV1 channels enhances the migratory activity. Most likely, the increase of the intracellular $\mathrm{Ca}^{2+}$ concentration following the $\mathrm{Ca}^{2+}$ influx via TRPV1 plays a key role in this process [25]. A number of calcium-sensitive targets that a part of the intracellular migration machinery such as myosin light chain kinase, gelsolin, nonmuscle $\alpha$-actinin or $\mathrm{Ca}^{2+}$-sensitive phosphatases like calcineurin or calpain, may be involved in mediating the stimulatory effect of TRPV1 activation on migration [45-50]. 
In addition, a dynamic reorganization of microtubules may also participate in the capsaicin-dependent stimulation of migration [51]. It has been shown that the C-terminal part of TRPV1 interacts with microtubules and thereby stabilizes them while the activation of TRPV1 channels promotes the disassembly of dynamic microtubules [52]. Assuming that TRPV1 channels, similarly to TRPC1 channels in neutrophils [53], are concentrated at the leading edge of HepG2 cells, activation of TRPV1 with capsaicin would reinforce the asymmetry of microtubules. Microtubules are more stable at the cell front than at the trailing edge [54]. Thus, a moderate activation of TRPV1 channels with low concentrations of capsaicin could modify the microtubule dynamics at the rear part of the cells in a way that allows an easier retraction of this cell pole and thereby stimulates migration. The disruption of the dynamic microtubule network following the application of high concentrations of capsaicin $(\geq 1 \mu \mathrm{M})$ could explain why only low doses of capsaicin $(\leq 100 \mathrm{nM})$ stimulate migration of HepG2 cells. Unfortunately, due to a considerable degree of cross reactivity of the TRPV1-antibodies with other unidentified proteins (see Fig. 3A), we were not able to determine the cell surface distribution of the endogenous TRPV1 channels in HepG2 cells and their possible colocalization with microtubules.

The role of HGF in increasing the sensitivity of HepG2 cells to stimulation with capsaicin is still unclear. Our data clearly show that the total amount of TRPV1 channels is not changed after HGF treatment (Fig. 3). Nonetheless, HGF evokes TRPV1 channel activity as revealed by our patch clamp experiments (Fig. 2). We suggest that HGF may create a permissive cellular environment that facilitates activation of TRPV1 channels in the plasma membrane or enhances recruitment of the already expressed channels to the plasma membrane. An alternative mechanism may involve the HGF-dependent upregulation of $\alpha_{2} \beta_{1}$ integrins [55] that mediate cell contacts to a collagen I matrix, which has been used in our study. Further studies are required to elucidate the underlying mechanism.

It is noteworthy that capsaicin elicits a sustained effect on HepG2 cell migration. The velocity is even slightly higher towards the end of the experiment than at its start. In patch clamp studies capsaicin-induced currents desensitized within a few seconds (Fig. 2B), reconfirming the well-documented rapid desensitization of TRPV1 channels to capsaicin $[44,56]$. The possible explanation of this discrepancy is that such a rapid desensitization is likely not to reflect the physiological conditions found in a cell. We therefore suggest that desensitization and recovery of TRPV1 channels are in an equilibrium during the prolonged exposure of HepG2 cells to capsaicin in our migration experiments. Desensitization and recovery of TRPV1 channels depend on their dephosphorylation/phosphorylation states and the synthesis of phosphatidylinositol 4,5-bisphosphate, respectively [57]. Inhibition of the $\mathrm{Ca}^{2+}$ sensitive phosphatase calcineurin strongly attenuates desensitization of TRPV1 channels [56]. A similar effect is also observed upon addition of ATP to the intracellular pipette solution and activation of protein kinase A [56,57]. Thus, the sustained stimulation of migration by capsaicin is probably due to a sustained elevation of TRPV1 channel activity. However, we cannot rule out the possibility that an increase of $\left[\mathrm{Ca}^{2+}\right]_{\mathrm{i}}$ triggers activation of transcription of early genes that are involved in cell migration [58].

\section{Acknowledgements}

This work was supported grants from the fund "Innovative Medical Research" of the University of Münster Medical School, the Deutsche Forschungsgemeinschaft to A.S. (Schw 407/9-2, -3) and by the Human Frontiers Science Program (HFSP Research Grant Ref. RGP 32/2004), the Belgian Federal Government, the Flemish Government, the Onderzoeksraad KU Leuven (GOA 2004/07, F.W.O. G.0136.00; F.W.O. G.0172.03, Interuniversity Poles of Attraction Program, Prime Ministers Office IUAP Nr. 3P4/23, Excellentiefinanciering EF/95/010.) to B.N. J.V. is a postdoctoral fellow of the FWO (Fonds voor Wetenschappelijk Onderzoek, Flanders).

\section{Appendix A. Supplementary data}

Supplementary data associated with this article can be found, in the online version, at doi:10.1016/j.ceca.2006.11. 005 .

\section{References}

[1] J. Lee, A. Ishihara, G. Oxford, B. Johnson, K. Jacobson, Regulation of cell movement is mediated by stretch-activated calcium channels, Nature 400 (1999) 382-386.

[2] S.M. Rafelski, J.A. Theriot, Crawling toward a unified model of cell mobility: spatial and temporal regulation of actin dynamics, Annu. Rev. Biochem. 73 (2004) 209-239.

[3] C. Brakebusch, R. Fassler, The integrin-actin connection, an eternal love affair, EMBO J. 22 (2003) 2324-2333.

[4] M.S. Bretscher, C. Aguado-Velasco, EGF induces recycling membrane to form ruffles, Curr. Biol. 8 (1998) 721-724.

[5] J. Schmoranzer, G. Kreitzer, S.M. Simon, Migrating fibroblasts perform polarized, microtubule-dependent exocytosis towards the leading edge, J. Cell Sci. 116 (2003) 4513-4519.

[6] S. Saadoun, M.C. Papadopoulos, M. Hara-Chikuma, A.S. Verkman, Impairment of angiogenesis and cell migration by targeted aquaporin-1 gene disruption, Nature 434 (2005) 786-792.

[7] A. Schwab, Function and spatial distribution of ion channels and transporters in cell migration, Am. J. Physiol. Renal Physiol. 280 (2001) F739-F747.

[8] C. Stock, A. Schwab, Role of the $\mathrm{Na} / \mathrm{H}$ exchanger NHE1 in cell migration, Acta Physiol. (Oxf.) 187 (2006) 149-157.

[9] E.J. Pettit, F.S. Fay, Cytosolic free calcium and the cytoskeleton in the control of leukocyte chemotaxis, Physiol. Rev. 78 (1998) 949967.

[10] A. Schwab, V. Nechyporuk-Zloy, A. Fabian, C. Stock, Cells move when ions and water flow, Pflugers Arch. 453 (2007) 421-432. 
[11] A. Schwab, F. Finsterwalder, U. Kersting, T. Danker, H. Oberleithner, Intracellular $\mathrm{Ca}^{2+}$ distribution in migrating transformed epithelial cells, Pflugers Arch. 434 (1997) 70-76.

[12] R.A. Brundage, K.E. Fogarty, R.A. Tuft, F.S. Fay, Calcium gradients underlying polarization and chemotaxis of eosinophils, Science 254 (1991) 703-706

[13] V. Dreval, P. Dieterich, C. Stock, A. Schwab, The role of $\mathrm{Ca}^{2+}$ transport across the plasma membrane for cell migration, Cell Physiol. Biochem. 16 (2005) 119-126.

[14] H. Komuro, P. Rakic, Orchestration of neuronal migration by activity of ion channels, neurotransmitter receptors, and intracellular $\mathrm{Ca}^{2+}$ fluctuations, J. Neurobiol. 37 (1998) 110-130.

[15] S. Yang, X.Y. Huang, $\mathrm{Ca}^{2+}$ influx through L-type $\mathrm{Ca}^{2+}$ channels controls the trailing tail contraction in growth factor-induced fibroblast cell migration, J. Biol. Chem. 280 (2005) 27130-27137.

[16] J.N. Rao, O. Platoshyn, V.A. Golovina, L. Liu, T. Zou, B.S. Marasa, D.J. Turner, J.X. Yuan, J.Y. Wang, TRPC1 functions as a store-operated $\mathrm{Ca}^{2+}$ channel in intestinal epithelial cells and regulates early mucosal restitution after wounding, Am. J. Physiol. Gastrointest. Liver Physiol. 290 (2006) G782-G792.

[17] B. Nilius, T. Voets, TRP channels: a TR(I)P through a world of multifunctional cation channels, Pflugers Arch. 451 (2005) 1-10.

[18] S.F. Pedersen, G. Owsianik, B. Nilius, TRP channels: an overview, Cell Calcium 38 (2005) 233-252.

[19] C. Montell, The TRP superfamily of cation channels, Sci. STKE 272 (2005) re3.

[20] D.E. Clapham, C. Montell, G. Schultz, D. Julius, International Union of Pharmacology. XLIII. Compendium of voltage-gated ion channels: transient receptor potential channels, Pharmacol. Rev. 55 (2003) 591-596.

[21] G. Baffy, L. Yang, G.K. Michalopoulos, J.R. Williamson, Hepatocyte growth factor induces calcium mobilization and inositol phosphate production in rat hepatocytes, J. Cell Physiol. 153 (1992) 332-339.

[22] T. Kawanishi, T. Kato, H. Asoh, C. Uneyama, K. Toyoda, K. Momose, M. Takahashi, Y. Hayashi, Hepatocyte growth factor-induced calcium waves in hepatocytes as revealed with rapid scanning confocal microscopy, Cell Calcium 18 (1995) 495-504.

[23] K.A. Stuart, S.M. Riordan, S. Lidder, L. Crostella, R. Williams, G.G. Skouteris, Hepatocyte growth factor/scatter factor-induced intracellular signalling, Int. J. Exp. Pathol. 81 (2000) 17-30.

[24] K. Matsumoto, T. Nakamura, Hepatocyte growth factor (HGF) as a tissue organizer for organogenesis and regeneration, Biochem. Biophys. Res. Commun. 239 (1997) 639-644.

[25] J. Vriens, A. Janssens, J. Prenen, B. Nilius, R. Wondergem, TRPV channels and modulation by hepatocyte growth factor/scatter factor in human hepatoblastoma (HepG2) cells, Cell Calcium 36 (2004) 19-28.

[26] M.J. Caterina, T.A. Rosen, M. Tominaga, A.J. Brake, D. Julius, A capsaicin-receptor homologue with a high threshold for noxious heat, Nature 398 (1999) 436-441.

[27] M.J. Caterina, A. Leffler, A.B. Malmberg, W.J. Martin, J. Trafton, K.R. Petersen-Zeitz, M. Koltzenburg, A.I. Basbaum, D. Julius, Impaired nociception and pain sensation in mice lacking the capsaicin receptor, Science 288 (2000) 306-313.

[28] S.E. Jordt, D. Julius, Molecular basis for species-specific sensitivity to "hot" chili peppers, Cell 108 (2002) 421-430.

[29] B. Nilius, J. Prenen, U. Wissenbach, M. Bodding, G. Droogmans, Differential activation of the volume-sensitive cation channel TRP12 (OTRPC4) and volume-regulated anion currents in HEK-293 cells, Pflugers Arch. 443 (2001) 227-233.

[30] H. Watanabe, J.B. Davis, D. Smart, J.C. Jerman, G.D. Smith, P. Hayes, J. Vriens, W. Cairns, U. Wissenbach, J. Prenen, V. Flockerzi, G. Droogmans, C.D. Benham, B. Nilius, Activation of TRPV4 channels (hVRL-2/mTRP12) by phorbol derivatives, J. Biol. Chem. 277 (2002) $13569-13577$.

[31] H. Watanabe, J. Vriens, J. Prenen, G. Droogmans, T. Voets, B. Nilius, Anandamide and arachidonic acid use epoxyeicosatrienoic acids to activate TRPV4 channels, Nature 424 (2003) 434-438.
[32] J. Vriens, H. Watanabe, A. Janssens, G. Droogmans, T. Voets, B. Nilius, Cell swelling, heat, and chemical agonists use distinct pathways for the activation of the cation channel TRPV4, Proc. Natl. Acad. Sci. U.S.A. (2004) 101.

[33] W. Liedtke, TRPV4 as osmosensor: a transgenic approach, Pflugers Arch. (2005) 451

[34] B. Nilius, J. Vriens, J. Prenen, G. Droogmans, T. Voets, TRPV4 calcium entry channel: a paradigm for gating diversity, Am. J. Physiol. Cell Physiol. 286 (2004) C195-C205.

[35] A. Schwab, A. Wulf, C. Schulz, W. Kessler, V. Nechyporuk-Zloy, M. Romer, J. Reinhardt, D. Weinhold, P. Dieterich, C. Stock, S.C. Hebert, Subcellular distribution of calcium-sensitive potassium channels (IK1) in migrating cells, J. Cell Physiol. 206 (2006) 86-94.

[36] G. Grynkiewicz, M. Poenie, R.Y. Tsien, A new generation of $\mathrm{Ca}^{2+}$ indicators with greatly improved fluorescence properties, J. Biol. Chem. 260 (1985) 3440-3450.

[37] M. Jin, D.M. Defoe, R. Wondergem, Hepatocyte growth factor/scatter factor stimulates $\mathrm{Ca}^{2+}$-activated membrane $\mathrm{K}^{+}$current and migration of MDCK II cells, J. Membr. Biol. 191 (2003) 77-86.

[38] S. Munevar, Y.L. Wang, M. Dembo, Regulation of mechanical interactions between fibroblasts and the substratum by stretch-activated $\mathrm{Ca}^{2+}$ entry, J. Cell Sci. 117 (2004) 85-92.

[39] R. Strotmann, C. Harteneck, K. Nunnenmacher, G. Schultz, T.D. Plant, OTRPC4, a nonselective cation channel that confers sensitivity to extracellular osmolarity, Nat. Cell Biol. 2 (2000) 695-702.

[40] W. Liedtke, Y. Choe, M.A. Marti-Renom, A.M. Bell, C.S. Denis, A. Sali, A.J. Hudspeth, J.M. Friedman, S. Heller, Vanilloid receptorrelated osmotically activated channel (VR-OAC), a candidate vertebrate osmoreceptor, Cell 103 (2000) 525-535.

[41] U. Wissenbach, M. Bodding, M. Freichel, V. Flockerzi, Trp12, a novel Trp related protein from kidney, FEBS Lett. 485 (2000) 127134

[42] S. Basu, P. Srivastava, Immunological role of neuronal receptor vanilloid receptor 1 expressed on dendritic cells, Proc. Natl. Acad. Sci. U.S.A. 102 (2005) 5120-5125.

[43] P.J. O'Connell, S.C. Pingle, G.P. Ahern, Dendritic cells do not transduce inflammatory stimuli via the capsaicin receptor TRPV1, FEBS Lett. 579 (2005) 5135-5139.

[44] D. McHugh, R.S. McMaster, R.G. Pertwee, S. Roy, A. Mahadevan, R.K. Razdan, R.A. Ross, Novel compounds that interact with both leukotriene B4 receptors and vanilloid TRPV1 receptors, J. Pharmacol. Exp. Ther. 316 (2006) 955-965.

[45] S. Rosenberg, A. Stracher, K. Burridge, Isolation and characterization of a calcium-sensitive alpha-actinin-like protein from human platelet cytoskeletons, J. Biol. Chem. 256 (1981) 12986-12991.

[46] M.P. Walsh, Calmodulin and the regulation of smooth muscle contraction, Mol. Cell Biochem. 135 (1994) 21-41.

[47] H.Q. Sun, M. Yamamoto, M. Mejillano, H.L. Yin, Gelsolin, a multifunctional actin regulatory protein, J. Biol. Chem. 274 (1999) 33179-33182.

[48] B. Hendey, C.B. Klee, F.R. Maxfield, Inhibition of neutrophil chemokinesis on vitronectin by inhibitors of calcineurin, Science 258 (1992) 296-299.

[49] A. Glading, D.A. Lauffenburger, A. Wells, Cutting to the chase: calpain proteases in cell motility, Trends Cell Biol. 12 (2002) 46-54.

[50] S.J. Franco, A. Huttenlocher, Regulating cell migration: calpains make the cut, J. Cell Sci. 118 (2005) 3829-3838.

[51] G. Liao, T. Nagasaki, G.G. Gundersen, Low concentrations of nocodazole interfere with fibroblast locomotion without significantly affecting microtubule level: implications for the role of dynamic microtubules in cell locomotion, J. Cell Sci. 108 (Pt 11) (1995) 34733483.

[52] C. Goswami, M. Dreger, H. Otto, B. Schwappach, F. Hucho, Rapid disassembly of dynamic microtubules upon activation of the capsaicin receptor TRPV1, J. Neurochem. 96 (2006) 254-266.

[53] A.L. Kindzelskii, H.R. Petty, Ion channel clustering enhances weak electric field detection by neutrophils: apparent roles of SKF96365- 
sensitive cation channels and myeloperoxidase trafficking in cellular responses, Eur. Biophys. J. 35 (2005) 1-26.

[54] K.J. Salaycik, C.J. Fagerstrom, K. Murthy, U.S. Tulu, P. Wadsworth, Quantification of microtubule nucleation, growth and dynamics in wound-edge cells, J. Cell Sci. 118 (2005) 41134122.

[55] N. Kawakami-Kimura, T. Narita, K. Ohmori, T. Yoneda, K. Matsumoto, T. Nakamura, R. Kannagi, Involvement of hepatocyte growth factor in increased integrin expression on HepG2 cells triggered by adhesion to endothelial cells, Br. J. Cancer 75 (1997) 47-53.
[56] D.P. Mohapatra, C. Nau, Regulation of $\mathrm{Ca}^{2+}$-dependent desensitization in the vanilloid receptor TRPV1 by calcineurin and cAMP-dependent protein kinase, J. Biol. Chem. 280 (2005) 13424-13432.

[57] B. Liu, C. Zhang, F. Qin, Functional recovery from desensitization of vanilloid receptor TRPV1 requires resynthesis of phosphatidylinositol 4,5-bisphosphate, J. Neurosci. 25 (2005) 4835-4843.

[58] P.O. Tran, L.E. Hinman, G.M. Unger, P.J. Sammak, A wound-induced $\left[\mathrm{Ca}^{2+}\right]_{\mathrm{i}}$ increase and its transcriptional activation of immediate early genes is important in the regulation of motility, Exp. Cell Res. 246 (1999) 319-326. 